\title{
Osteoclast Formation within a Human Co-Culture System on Bone Material as an In Vitro Model for Bone Remodeling Processes
}

\author{
Franziska V. Schmid ${ }^{1,2,+}$, Claudia Kleinhans ${ }^{3,+}$, Freia F. Schmid ${ }^{1,4}$ and Petra J. Kluger ${ }^{1,5, *}$ \\ 1 Fraunhofer Institute for Interfacial Engineering and Biotechnology IGB, 70569 Stuttgart, Germany; \\ f.schmid@em.uni-frankfurt.de (F.V.S.); freia.schmid@isc.fraunhofer.de (F.F.S.) \\ 2 Institute for Molecular Biosciences, Goethe University, 60438 Frankfurt, Germany \\ 3 Institute for Interfacial Process Engineering and Plasma Technology IGVP, University of Stuttgart, \\ 70174 Stuttgart, Germany; c.kleinhans@gmx.de \\ 4 Fraunhofer Institute for Silicate Research ISC, 97082 Wuerzburg, Germany \\ 5 School of Applied Chemistry, Reutlingen University, 72762 Reutlingen, Germany \\ * Correspondence: petra.kluger@reutlingen-university.de; Tel.: +49-7121-271-2061 \\ + These authors contributed equally to this work.
}

Received: 31 December 2017; Accepted: 12 March 2018; Published: 18 March 2018

\begin{abstract}
Bone remodeling can be mimicked in vitro by co-culture models. Based on bone cells, such co-cultures help to study synergistic morphological changes and the impact of materials and applied substances. Hence, we examined the formation of osteoclasts on bovine bone materials to prove the bone resorption functionality of the osteoclasts in three different co-culture set-ups using human monocytes (hMCs) and (I) human mesenchymal stem cells (hMSCs), (II) osteogenic differentiated hMSCs (hOBs), and (III) hOBs in addition of soluble monocyte-colony stimulating factor (M-CSF) and cytokine receptor activator of NFKB ligand (RANKL). We detected osteoclast-specific actin morphology, as well as the expression of cathepsin K and CD51/61 in single cells in set-up II and in numerous cells in set-up III. Resorption pits on bone material as characteristic proof of functional osteoclasts were not found in set-up I and II, but we detected such resorption pits in set-up III. We conclude in co-culture models without M-CSF and RANKL that monocytes can differentiate into osteoclasts that show the characteristic actin structures and protein expression. However, to receive functional bone resorbing osteoclasts in vitro, the addition of M-CSF and RANKL is needed. Moreover, we suggest the use of bone or bone-like materials for future studies evaluating osteoclastogenesis.
\end{abstract}

Keywords: bone resorption; human monocytes; osteoclasts; osteoclastogenesis; bone remodeling; co-culture model; in vitro test system

\section{Introduction}

Bone remodeling is an important process that maintains the homoeostasis of bone tissue in vivo. Osteoprogenitors, osteoblasts, osteocytes, osteoclasts, and bone lining cells are the prevalent cells that interact in a complex orchestrated way to maintain and adjust bone tissue [1]. The remodeling process is influenced by several factors such as environmental cues, soluble factors, and cell interactions [2]. As osteoblasts and osteoclasts are the key players in bone remodeling processes and are closely co-regulated, the inclusion of both cell types within an in vitro model that simulates the bone remodeling process is a promising approach. In vivo, human monocytes (hMCs) derive from hematopoietic stem cells that occur in the blood flow [3,4]. They are short living cells and can be activated at the particular site by cytokine expression of supporting cells [5]. The question is whether this specific regulation can be postposed in vitro. As known, the growth factor cytokine receptor 
activator of NFKB ligand (RANKL) is responsible for osteoclast differentiation, function, and survival; osteoclasts can be generated in vitro by RANKL addition in mono culture to monocytes [6,7]. Characteristics of differentiated osteoclasts are the cathepsin K and CD51/61 $\alpha v \beta$-integrin expression. $\alpha \mathrm{v} \beta$-integrin is a receptor for vitronectin, whereas cathepsin $\mathrm{K}$ is a lysosomal cysteine proteases, which is able to break down bone cartilage by catabolizing collagen type I, elastin, and gelatin [8,9]. Functional osteoclasts are bone-resorbing cells. Even in vitro osteoclasts are able to develop this resorption activity when they are cultured on bone or bone-like materials [10]. To simulate the in vivo situation of osteoclastogenesis, a co-culture system with human monocytes or osteoclasts and supporting cells such as mesenchymal stem cells (MSCs) or osteoblasts in appropriate culture conditions, especially media supplementation and bone or bone-like materials, have to be combined. In several studies, co-culture experiments were performed to examine signaling pathways, osteogenesis, or osteoclastogenesis. Indirect co-cultures were performed based on the use of conditioned medium, collected from alternative cell culture of breast cancer cells to study osteoclastogenesis induction of peripheral blood mononuclear cells (PBMCs) and the metastatic bone microenvironment [11]. A 3D-dynamic co-culture set-up with osteoblasts and osteoclasts was established to simulate jawbone microenvironment in vitro [12]. Moreover, local osteoclastogenesis induced by cellular crosstalk between keratinocytes and fibroblasts was recognized [13]. Different culture models were built-up to allow the exchange of soluble factors [14-16]. However, these conditions eliminate direct cell-cell interactions. A set-up in which monocytes/osteoclasts and osteoblasts are cultured simultaneously maintains cell-cell interactions and the exchange of soluble factors that are postulated to be essential for the stimulation of osteoclast differentiation [6]. Some studies evaluated the influence of monocytes on the osteogenic differentiation of MSCs [17-20]. It could be shown that factors such as bone morphogenetic protein 2 are secreted by monocytes that induce an osteogenic lineage commitment of MSCs [19]. Furthermore, the influence of stem cells or osteoblasts on osteoclastogenesis in a direct in vitro co-culture model was performed and revealed the formation of osteoclast-like cells [21,22]. However, an extensive evaluation of culture conditions, as well as the evidence of active bone resorbing osteoclasts by using bone or bone-like materials, is still incomplete for in vitro co-culture systems. Thus, we compared different co-culture conditions on bone slices (BS) that aimed to achieve functional human osteoclasts (hOCs) with characteristic actin morphology and the expression of cathepsin K and CD51/61. Moreover, we focused on the bone resorption functionality of osteoclasts in our co-culture set-ups by analyzing the appearance of resorption pits on bone materials.

\section{Materials and Methods}

\subsection{Isolation of Human Monocytes}

hMCs were isolated as described previously in Kleinhans et al. 2015 [10]. Briefly, cells were obtained by Ficoll-Paque ${ }^{\mathrm{TM}}$ Plus (GE Healthcare; Chalfont St Giles, UK) density gradient centrifugation at $485 \times \mathrm{g}$ for $30 \mathrm{~min}$ at $4{ }^{\circ} \mathrm{C}$ (without brake). Buffy coats were mixed with blood buffer beforehand that consisted of $4 \mathrm{~g} / \mathrm{L} \mathrm{NaCl}, 0.2 \mathrm{~g} / \mathrm{L} \mathrm{KCl}, 0.2 \mathrm{~g} / \mathrm{L} \mathrm{KH}_{2} \mathrm{PO}_{4}, 1.15 \mathrm{~g} / \mathrm{L} \mathrm{Na}_{2} \mathrm{HPO}_{4}, 14.7 \mathrm{~g} / \mathrm{L} \mathrm{C}_{6} \mathrm{H}_{9} \mathrm{Na}_{3} \mathrm{O}_{9}$ (sodium citrate dehydrate), and $5.0 \mathrm{~g} / \mathrm{L}$ bovine serum albumin (BSA). $\mathrm{hMCs}$ were gathered from the resulting interface by centrifugation and were washed three times with blood buffer $(200 \times g$, $7 \mathrm{~min})$. Erythrocytes were lysed by adding $10 \mathrm{~mL}$ erythrocyte lysis buffer $(8.29 \mathrm{~g} / \mathrm{L} \mathrm{NaCl} 1.0 \mathrm{~g} / \mathrm{L}$ $\mathrm{KHCO}_{3}, 0.0372 \mathrm{~g} / \mathrm{L}$ ethylenediaminetetraacetic acid (EDTA)) for $10 \mathrm{~min}$ at room temperature. After centrifugation at $200 \times g$ for $7 \mathrm{~min}$, another washing step was performed as described above. Finally, the cell suspension was transferred at a density of $2.5 \times 10^{5} \mathrm{cells} / \mathrm{cm}^{2}$ in DMEM with L-Glutamine and D-Glucose (Biochrom AG; Berlin, Germany) that contained 10\% fetal calf serum (FCS) (Invitrogen; Karlsruhe, Germany), so called basic medium, and $50 \mathrm{ng} / \mathrm{mL}$ M-CSF (HumanZyme; Chicago, IL, USA) into culture flasks. An adhesion time of $1.5 \mathrm{~h}$ was performed before rinsing cells with PBS. Then, the basic medium was changed every 2-3 days. 


\subsection{Induction of Osteoclastogenesis}

After the expansion time of 7 days, the hMCs were incubated with PBS/EDTA (Life Technologies, Darmstadt, Germany) for $10 \mathrm{~min}$ and detached via trypsin/EDTA incubation of $10 \mathrm{~min}$ (Life Technologies, Darmstadt, Germany). Passage 1 was seeded with a cell density of $1 \times 10^{5} \mathrm{cells} / \mathrm{cm}^{2}$ on 48 well tissue culture polystyrene (TCPS) and $1 \times 10^{5}$ cells on bovine bone slices (BS: Boneslices.com, Jelling, Denmark). For osteoclastogenic differentiation, Dulbecco's Modified Eagle Medium (DMEM) contained 10\% FCS, $50 \mathrm{ng} / \mathrm{mL}$ M-CSF and $50 \mathrm{ng} / \mathrm{mL}$ RANKL (R\&D Systems, Wiesbaden, Germany). This osteoclastogenic medium (OC medium) was replaced every 2-3 days. Analyses were done after 14 days of differentiation.

\subsection{Activated Cell Scanning via Flow Cytometry}

The cell population after monocyte isolation was analyzed via differentiation cluster (CD) markers: CD14, CD45, and CD51/61 (Table 1). $1 \times 10^{5}$ cells per antibody combination were used. Cells were taken before plastic adhesion (PA), $1.5 \mathrm{~h}$ after PA, and after 7 days of culture in basic medium. Cells were centrifuged at $200 \times g$ for $5 \mathrm{~min}$. Pellets were resuspended in coloring buffer (BD-Biosciences, Heidelberg, Germany) and again centrifuged at $200 \times g$ for $5 \mathrm{~min}$. This step was done twice, and the pellets were resuspended again in coloring buffer. FC-blocker (FCR Blocking Reagent human 120000442, Miltenyi Biotec, Bergisch-Gladbach, Germany) was added for 8 min to prevent unspecific staining. The cells were washed two times with FACS-buffer (BD Pharmingen ${ }^{\mathrm{TM}}$, San Diego, CA, USA) and centrifuged at $200 \times g$ for $5 \mathrm{~min}$. Cells were divided into five aliquots for the fluorescence staining of CD14, CD45, CD51/61 (CD14 APC anti human $(555,399)$ BD Pharmingen ${ }^{\mathrm{TM}}{ }^{\text {, Heidelberg, }}$ Germany; CD45-PE (A07783), Beckmann Coulter, Marseille, France,; Fluorescein isothiocyanate (FITC) anti human CD51/61 (555,505), BD Pharmingen ${ }^{\mathrm{TM}}$, Heidelberg, Isotype: IgG2a APC Mouse IgG2a, K $(555,576)$, BD Pharmingen ${ }^{\mathrm{TM}}$, Heidelberg, Isotype: IgG1 (Mouse)-PE (A07796), Beckmann Coulter, Marseille, France; Isotype: FITC Mouse IgG1 Isotype Control Fluorescein Conjugated (IC002F), R\&D Systems, Minneapolis, MN, USA) and respective controls (Table 1) for $20 \mathrm{~min}$, followed by washing steps with FACS-buffer and centrifugation at $200 \times g$ for $5 \mathrm{~min}$, done twice. Finally, fixation of the stained cells followed with BD-fixation-solution (BD-Biosciences, Heidelberg, Germany) and measurements at the BD-FACS-Verse ${ }^{\mathrm{TM}}$ were conducted.

Table 1. Used antibody combination for activated cell scanning via flow cytometry.

\begin{tabular}{cc}
\hline Aliqout & Antibody Combination \\
\hline 1 & Autofluorescence (undyed control) \\
2 & $51 / 61$ FITC, IgG1-PE, IgG2a-APC \\
3 & IgG1 FITC, 45-PE, IgG2a-APC \\
4 & IgG1 FITC, IgG1-PE, CD14-APC \\
5 & 51-61 FITC, 45-PE, CD14-APC \\
\hline
\end{tabular}

\section{4. hMSCs Isolation and Culture}

hMSCs were isolated from human bone aspirate, which was purchased by Lonza and stored in liquid nitrogen [23]. The cells were defrosted on ice and seeded in MSCBM-CD ${ }^{\mathrm{TM}}$ that contained $1 \%$ MSC-GM-CD ${ }^{\mathrm{TM}}$ Supplement, 2\% FCS, and 1\% Pen/Strep (Lonza Group Ltd., Basel, Switzerland) (stem cell medium). At $75 \%$ confluence, the cells were detached with trypsin/EDTA for 5 min and seeded $\left(1 \times 10^{4} \mathrm{cells} / \mathrm{cm}^{2}\right)$. Further culture was done in basic medium or osteoblastogenic differentiation medium as described below.

\subsection{Induction of Osteoblastic Differentiation of hMSCs}

The differentiation of hMSCs was done in osteoblastogenic medium (DMEM with L-glutamine and D-glucose, 10\% FCS, 1\% Pen/Strep (Gibco Invitrogen, Karlsruhe, Germany, D), $10 \mathrm{mM}$ 
$\beta$-glycerophosphate (Sigma-Aldrich, Steinheim, Germany, D), $50 \mu \mathrm{g} / \mathrm{mL}$ L-ascorbic acid-2-phosphate (Sigma-Aldrich, Steinheim, Germany), and $100 \mathrm{nM}$ dexamethasone (Sigma-Aldrich, Steinheim, Germany). The osteoblastogenic medium (OB medium) was changed every 2-3 day until day $14-28$, respectively.

\subsection{Co-Culture of hMSCs and hMCs on TCPS and Cortical Bone Slices}

The bone slices (BS) shipped in 70\% ethanol were transferred to 48 well TCPS plates, washed in PBS $^{-}$(Biochrom, Berlin, Germany), and dried overnight. Three co-culture models were build-up on bone slices (Scheme 1):

I. hMSCs with hMCs: the complete co-culture was done in basic medium without adding differentiation factors.

II. hOBs with hMCs: hMSCs were differentiated with OB medium until day 13. After hMCs were seeded on top of the generated hOBs, the co-culture was kept in basic medium.

III. hOBs with hOCs: hMSCs were differentiated with OB medium until day 13. After seeding hMCs on top of hOBs, the co-culture was performed in OC medium by addition of osteoclastogenic differentiation factors (M-CSF and RANKL).

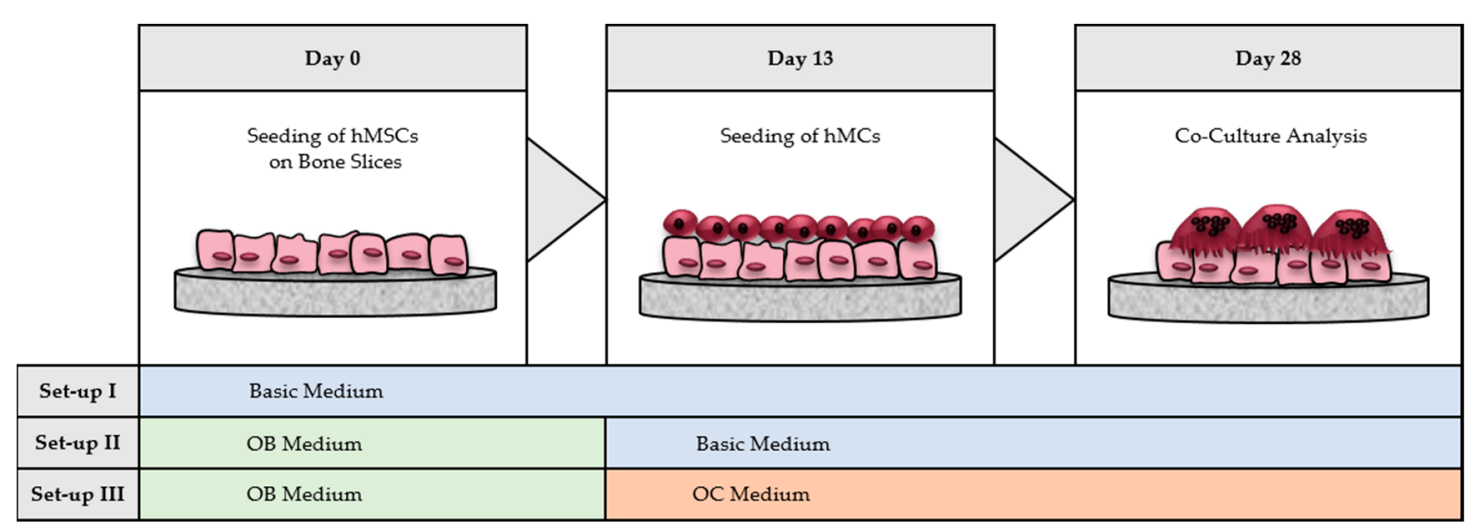

Scheme 1. Co-culture set-ups on bone slices (BS). $8 \times 10^{3}$ hMSCs were seeded at day 0 on bovine bone material. Three different culture-models were build-up, whereas in model II and III hMSCs were differentiated to hOBs by medium supplementation. At day $13,1 \times 10^{5} \mathrm{hMC}$ s were seeded on top of the hMSCs/hOB and were co-cultured until day 28 in basic medium (model I and II) or in OC medium (model III).

In all three models, $8 \times 10^{3} \mathrm{hMSC}$ s were seeded first on BS, respectively. Medium was exchanged every 2-3 days for all three models. At day $13,1 \times 10^{5} \mathrm{hMC}$ s were seeded on top of the hMSCs/hOBs. Medium was replaced every 2-3 days until day $14 / 28$, respectively.

\subsection{Fluorescence Staining}

To evaluate cell morphology, differentiation, and multi-nuclearity of osteoclasts, cells were stained for $\mathrm{f}$-actin, vinculin, cathepsin $\mathrm{K}$, and CD51/61 ( $\alpha \mathrm{v} \beta$-Integrin).

Staining of the f-actin and vinculin (Table 2): The samples were washed with PBS, fixed with Roti ${ }^{\circledR}$ Histofix (Roth; Karlsruhe, Germany), and permeabilized with $0.1 \%$ Triton X-100 (Sigma-Aldrich; Steinheim, Germany) in PBS for $10 \mathrm{~min}$. The fixed cells were stained with alexa fluor 546 phalloidin diluted 1:50 for $1 \mathrm{~h}$. Cells were rinsed with PBS and stained with anti-vinculin-FITC-conjugate 1:100 for $1.5 \mathrm{~h}$. Cells were washed again in PBS and the cell nuclei were counter stained with DAPI (4',6-Diamidin-2-phenylindol) 1:1000. Rinsed with PBS and covered with PBS, the samples were analyzed by laser scanning microscopy (Zen 2.3, Carl Zeiss, Jena, Germany). 
Table 2. Antibodies and fluorophores applied for immunofluorescence.

\begin{tabular}{|c|c|c|c|}
\hline Antibody/Fluorophore & Product Code & Manufacturer & Registered Office \\
\hline $\begin{array}{l}\text { Purified Mouse IgG3, Isotype Clone } \\
\text { MG3-35 }\end{array}$ & 401302 & BioLegend Biozol & Eching (D) \\
\hline Maus IgG1 & X0931 & DAKO GmbH & Glostrup (DK) \\
\hline $\begin{array}{l}\text { Rabbit IgG, monoclonal isotype control } \\
\text { SP137 }\end{array}$ & ab128142 & Abcam & Cambridge (USA) \\
\hline Antibody-Diluent & S302283-2 & Acris $\mathrm{GmbH}$ & Herford (D) \\
\hline $\begin{array}{c}\text { Actin staining } \\
\text { Alexa Fluor 546-Phalloidin }\end{array}$ & A22283 & Invitrogen & Karlsruhe (D) \\
\hline $\begin{array}{c}\text { Vinculin staining } \\
\text { Monoclonal Anti-Vinculin-FITC antibody }\end{array}$ & F7053-500UL & Sigma-Aldrich & Steinheim (D) \\
\hline $\begin{array}{c}\text { CD51/61 staining } \\
\text { Anti-CD51 + CD61 antibody [23C6] } \\
\left.\text { Alexa Fluor F(ab' }{ }_{2}\right)_{2} 488 \text { Fragment of Goat } \\
\text { Anti-Mouse IgG }(\mathrm{H}+\mathrm{L}) \text { Antibody }\end{array}$ & $\begin{array}{l}\text { ab34226 } \\
\text { A-11017 }\end{array}$ & $\begin{array}{c}\text { Abcam } \\
\text { Life technologies }\end{array}$ & $\begin{array}{c}\text { Cambridge (USA) } \\
\text { Darmstadt (D) }\end{array}$ \\
\hline $\begin{array}{c}\text { Cathepsin K } \\
\text { Anti-Cathepsin K antibody } \\
\text { Alexa Fluor } \mathrm{F}\left(\mathrm{ab}^{\prime}\right)_{2} 555 \\
\text { DAPI }\left(4^{\prime} \text {,6-Diamidin-2-phenylindol }\right)\end{array}$ & $\begin{array}{l}\text { ab19027 } \\
\text { A-21430 } \\
18860.01\end{array}$ & $\begin{array}{c}\text { Abcam } \\
\text { Life technologies } \\
\text { Serva Electrophoresis GmbH }\end{array}$ & $\begin{array}{c}\text { Cambridge (USA) } \\
\text { Darmstadt (D) } \\
\text { Heidelberg (D) }\end{array}$ \\
\hline
\end{tabular}

Immunofluorescence staining of cathepsin $\mathrm{K}$ and CD51/61 (Table 2): Samples were fixed in Roti ${ }^{\circledR}$ Histofix, as described above, incubated with $3 \%$ BSA, washed with PBS, and permeabilized with $0.1 \%$ Triton $X$ for $10 \mathrm{~min}$. Samples were washed again with wash buffer and incubated for $60 \mathrm{~min}$ with primary antibodies of CD51/61 and cathepsin K 1:100. After rinsing with wash buffer, cells were incubated in secondary antibody solutions of CD51/61 and cathepsin K, 1:500. The counter staining of the cell nuclei and the analyses were carried out as described before.

\subsection{Vybrant ${ }^{\mathrm{TM}}$ Cell Labeling}

To analyze cell amount and cell distribution on BS, hMSCs were labeled by Dil (red) and hMCs by $\mathrm{DiO}$ (green). Therefore, the three co-culture set-ups were performed as described above. Before seeding, the cells were stained with Vybrant ${ }^{\mathrm{TM}}$ Cell Labeling Solutions (Gibco-Invitrogen, Karlsruhe, Germany). Cells were centrifuged at $450 \times g$ for $5 \mathrm{~min}$ and resuspended in FCS free basic medium at a concentration of $1 \times 10^{6}$ cells $/ \mathrm{mL} .5 \mu \mathrm{L}$ Dil Vybrant ${ }^{\mathrm{TM}}$ Cell Labeling Solution $(630-700 \mathrm{~nm}$, red-orange) was gently mixed with hMSCs. The same was done with hMCs and Vybrant DiO Cell Labeling Solution (480-650 nm, green). After an incubation time of $20 \mathrm{~min}$ at $37^{\circ} \mathrm{C}$, two washing steps followed with basic medium and centrifugation at $450 \times g$ for $5 \mathrm{~min}$. The staining was used for co-cultures on BS and 48 well TCPS.

\subsection{Scanning Electron Microscopy (SEM)}

After washing the cells with PBS, samples were fixed in $2 \%$ glutaraldehyde solution (Sigma Aldrich; Steinheim, Germany) for $45 \mathrm{~min}$ at room temperature, dehydrated through a graded ethanol series (25\%, 50\%, 75\%, 96\% ethanol, 2-propanol; 5 min each), air-dried, sputter coated with a thin layer of gold, and observed by SEM (LEO 1530-VP; Carl Zeiss, Jena, Germany).

To examine the resorption of the bone matrix, the cells were removed from the surface by incubation in $0.5 \%$ trypsin-EDTA (Invitrogen; Karlsruhe, Germany) for $20 \mathrm{~min}$ at $37^{\circ} \mathrm{C}$, followed by lysis with 1\% Triton X-100 (Sigma-Aldrich; Steinheim, Germany) for $1 \mathrm{~h}$ at the plate shaker. Subsequently, the samples were treated as explained above for SEM. The diameter of the detected resorption pits was measured on three different SEM images per culture condition at 18 different pits. 


\subsection{Statistics}

Each experiment was repeated at least three times (three biological replicates with three technical replicates each). Statistical significance was assessed by the software OriginPro $8 \mathrm{G}$ using one factor analysis of variance (ANOVA) applying post hoc fishers Least Significant Difference (LSD) test. The data were expressed as mean values \pm standard deviation.

\section{Results}

The aim of this study was to evaluate the osteoclastogenesis of hMCs on bone slices, induced by hMSCs/hOBs in a co-culture system that focused on characteristic actin formation, CD51/61 expression, and bone resorption functionality. Primary hMSCs and hMCs were isolated and characterized by different techniques. As control, differentiation was induced by medium supplements in order to generate hOBs or hOCs.

\subsection{Characterization of Human Monocytes}

Buffy coats were used to isolate the hMCs. These Buffy coats consist of erythrocytes, lymphocytes, monocytes, and plasma. For isolation, a cell density gradient centrifugation was performed (DGC). In addition, erythrocytes were lysed and lymphocytes were removed while monocytes were adhering onto polystyrene surfaces. Characterizations of the hMCs were done via flow cytometry analysis during isolation after DGC, $1.5 \mathrm{~h}$ plastic adhesion, and 7 days expansion after plastic adhesion (Table 3). The expression of characteristic proteins to identify monocytes like CD14 [24,25] and CD45 for leukocytes [26] was analyzed. Furthermore, the expression of CD51/61 as characteristic proteins of osteoclasts was measured, whereby CD51 is the vitronectin receptor (Integrin $\alpha-V$ ) and CD61 is the integrin $\beta-3$ [27-30]. The expression of CD 14 increased during the different isolation steps. CD45 was shown in high concentrations over all three isolation steps, whereas less than $1 \%$ of the cells expressed CD51/61.

Table 3. Characterization of hMCs by flow cytometry. Cells were analyzed after density gradient centrifugation (DGC), $1.5 \mathrm{~h}$ after plastic adhesion (PA) and after 7 days of culture in basic medium. During the culture period, nearly all hMCs expressed CD45, and the level of CD14 increased, whereas osteoclast-specific CD51/61 was expressed by less than $1 \%$ of the cells.

\begin{tabular}{cccc}
\hline & CD14 (\%) & CD45 (\%) & CD51/61 (\%) \\
\hline DGC & $21.00 \pm 13.35$ & $96.66 \pm 0.98$ & $0.22 \pm 0.12$ \\
1.5 h PA & $34.60 \pm 9.37$ & $95.52 \pm 1.35$ & $0.25 \pm 0.12$ \\
1.5 h PA and 7 days cultured & $37.43 \pm 2.52$ & $99.42 \pm 0.66$ & $0.40 \pm 0.53$ \\
\hline
\end{tabular}

\subsection{Comparison of $h M C$ s and $h O C$ s on TCPS and BS}

For the fluorescence staining, hMCs were differentiated into hOCs in medium containing M-CSF and RANKL for 14 days on BS and TCPS or kept undifferentiated in basic medium (Figure 1). On both materials, cells with an osteoclast-like, multinucleated morphology occurred, if cultured in OC medium (Figure 1A,B). Cells, cultured in basic medium for 14 days, kept their hMC like phenotype.

Changes in the cytoskeleton, such as the formation of podosomes, filopodia, and, especially, actin rings, are characteristic of osteoclast-like cells. Therefore, we used staining of actin and vinculin. Actin-rings were detectable in active osteoclasts (Figure 1A). $\alpha v \beta$-Integrin (CD51/61) was detectable on both materials. Cathepsin K expression was less in osteoclast-like cells on TCPS (Figure 1B). Imaging resorption-activity of hOCs was evaluated by SEM. On BS former cultured with hOC resorption pits were detected (Figure 1C). 


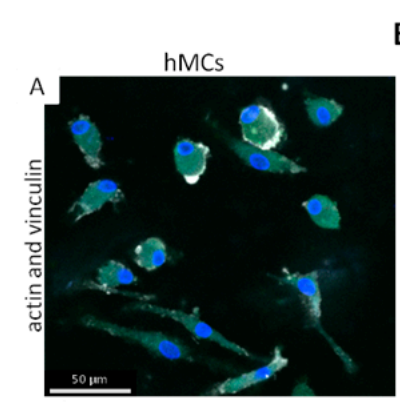

BS
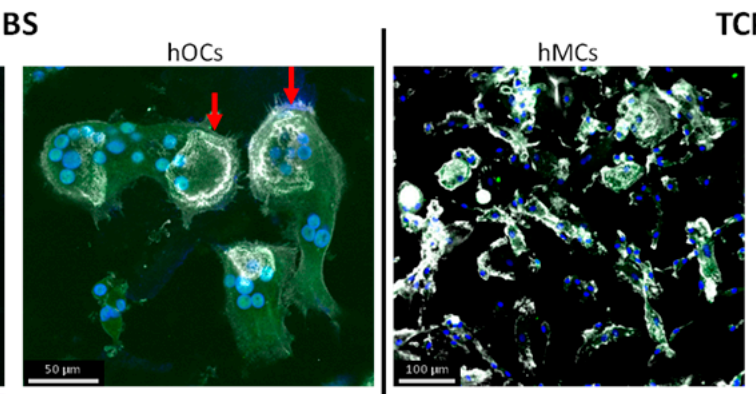

TCPS
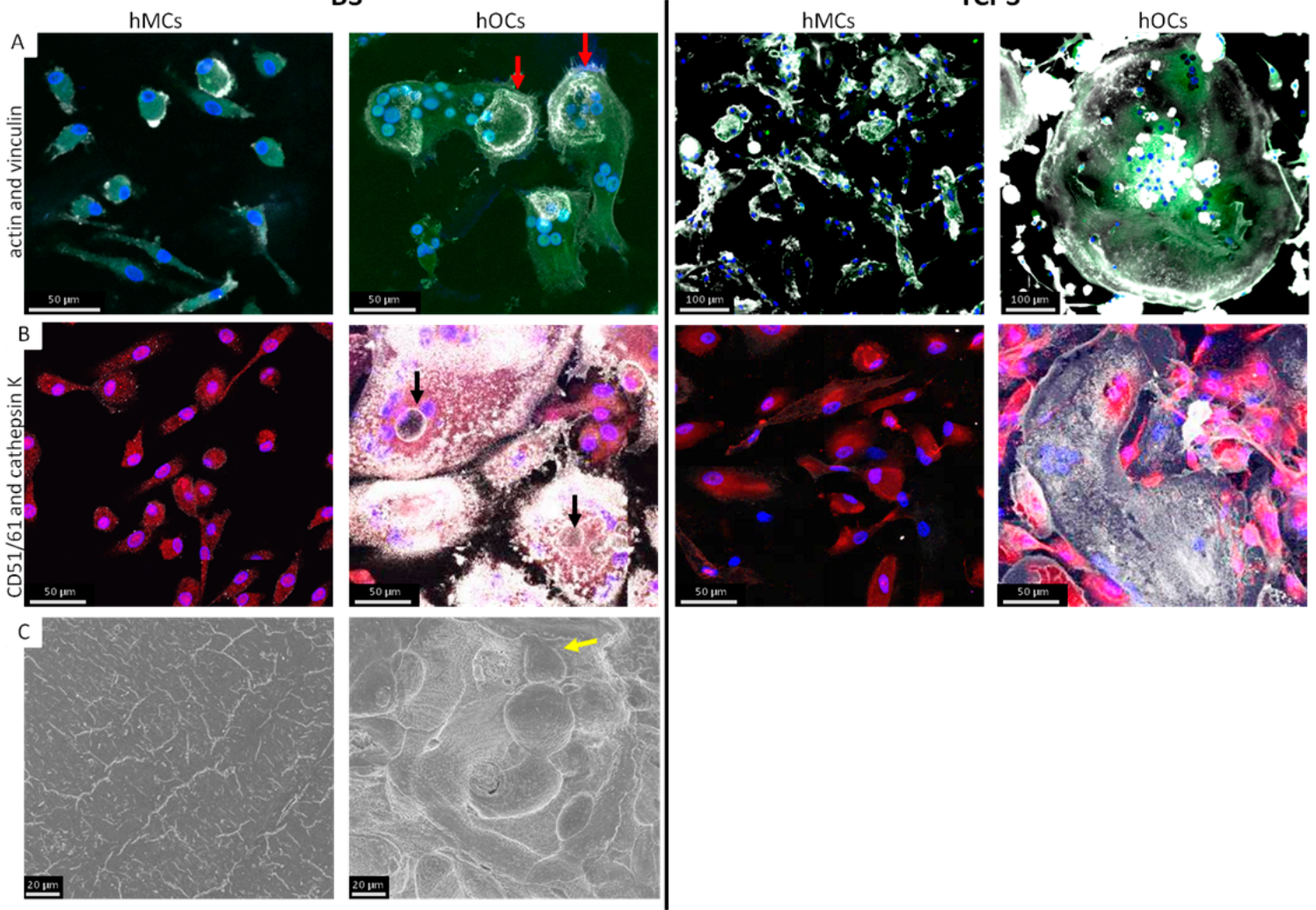

Figure 1. Comparison of hMCs and hOCs on BS and TCPS. The staining was performed after 14 days of cell culture with OC and basic medium, respectively. On both materials osteoclast-like large multinucleated cells occurred. The typical actin rings (red arrow) were only formed on BS (actin: white; vinculin: green) and by cells cultured with OC medium (A). The CD51/61 expression was shown on both materials (CD51/61: white; cathepsin K: red) but sealing zones were only formed on BS (black arrow) (B). Cells on BS were removed and resorption pits were visible in SEM-analysis (C) for hMCs in OC medium (yellow arrow).

\subsection{Characterization of the Co-Culture Set-Ups on BS}

To examine osteoclastogenesis, three co-culture models were built-up on BS. In model I, hMSCs were pre-cultured in basic medium for 13 days. hMCs were added and co-cultured for additional 14 days in basic medium. In model II, hMSCs were pre-cultured for 13 days in osteoblastogenic medium. hMCs were added and co-cultured for additional 14 days in basic medium. The conditions in model III were analogous to model II; however, the co-culture was performed in osteoclastogenic differentiation medium containing M-CSF and RANKL. The characterization of osteoclastogenesis was performed by fluorescent staining and SEM analysis on the bone material.

\subsubsection{Distribution of hMCs and hMSC on BS in Our Co-Culture Set-Ups}

The Vybrant ${ }^{\mathrm{TM}}$ cell labeling was applied to obtain an overview of the distribution of hMCs and hMSCs on BS after 1 and 14 days of co-culture (Figure 2). Red stained hMSCs and green stained hMCs were detected in all three co-culture models directly after seeding (Figure 2A) or after 14 days (Figure 2B), whereby more hMSCs than hMCs were seen in all co-culture models. 

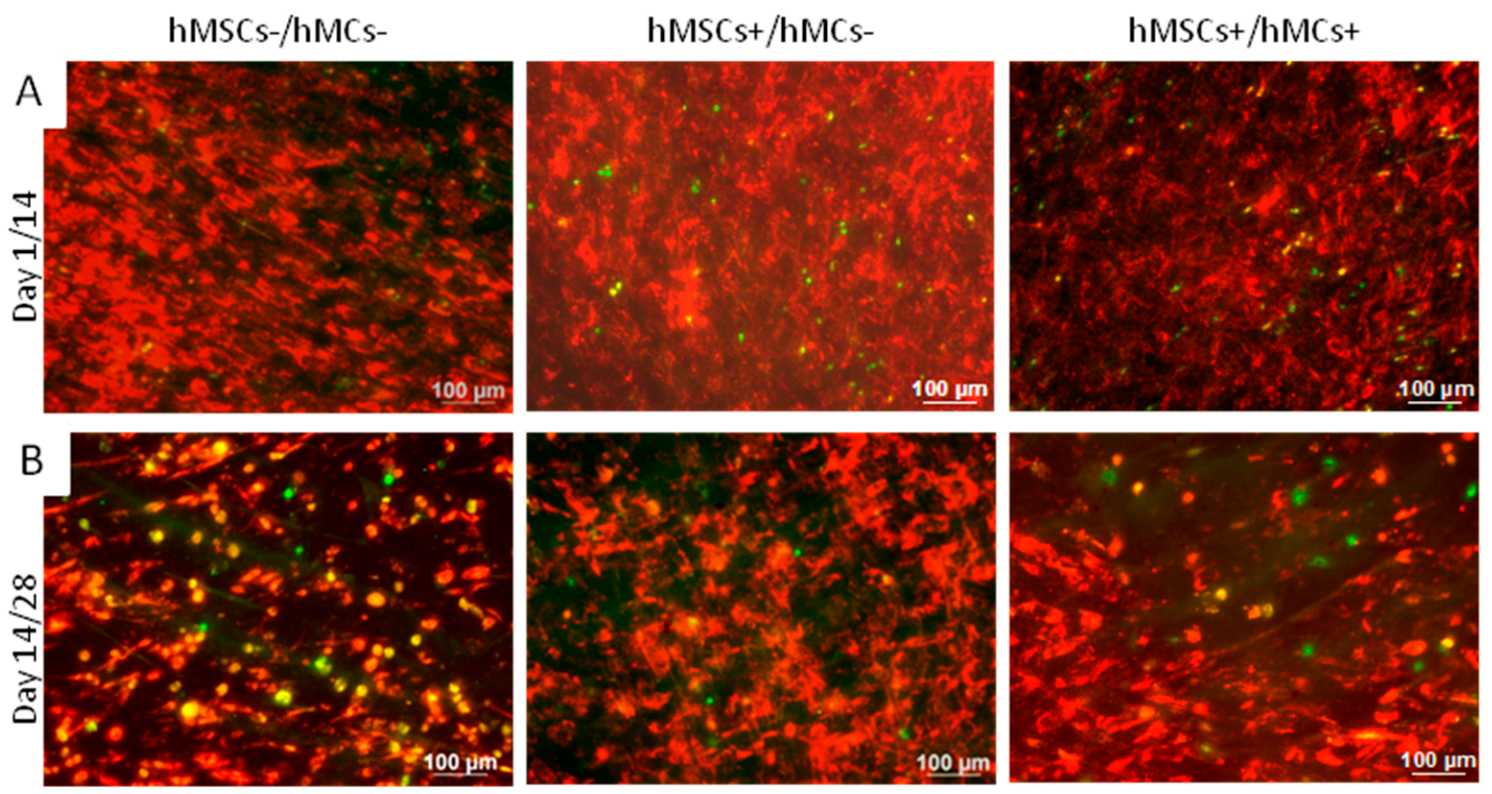

Figure 2. Vybrant ${ }^{\mathrm{TM}}$ cell labeling of hMCs (green) and hMSCs (red) to verify cell distribution within three co-culture set-ups after 1 day (A) and 14 days (B) of co-culture. Much more hMSCs were detected than hMCs in all set-ups at both time points. "+": These cells were cultured in medium supplemented with factors that supported differentiation. "-": These cells were cultured in medium not supplemented with factors that supported differentiation.

\subsubsection{Morphological Analysis of the Osteoclastogenesis on BS in Co-Culture Set-Ups}

To evaluate the morphology of the different cell-types during the co-cultures, f-actin and vinculin, as well as CD51/61 and cathepsin K, were stained after 28 days of culture/14 days of co-culture (Figure 3). In the mono cell-culture controls, the typical actin morphology for osteoclasts (Figure 3A) and CD51/61 expression (Figure 3B) was only found for hMC+.

The formation of osteoclast-specific actin (white) rings was seen in co-culture model III, whereby in model II only sporadic changes in actin arrangement were detected. No osteoclast-specific actin formation was detected in model I (Figure 3C). hMSC specific actin fibers with either diffuse vinculin staining or staining at the end of the fibers were observed in all three co-culture set-ups.

CD51/61 (red) and cathepsin K (white) as typical proteins for osteoclasts occurred in cells in all three co-culture models (Figure 3D). For cathepsin K, there were only sporadic cells stained in co-culture model I and II, but numerous cathepsin K-positive cells were seen in co-culture set-up III. Furthermore, in model III, larger and more multinucleated cells were detected as in model I and II. 

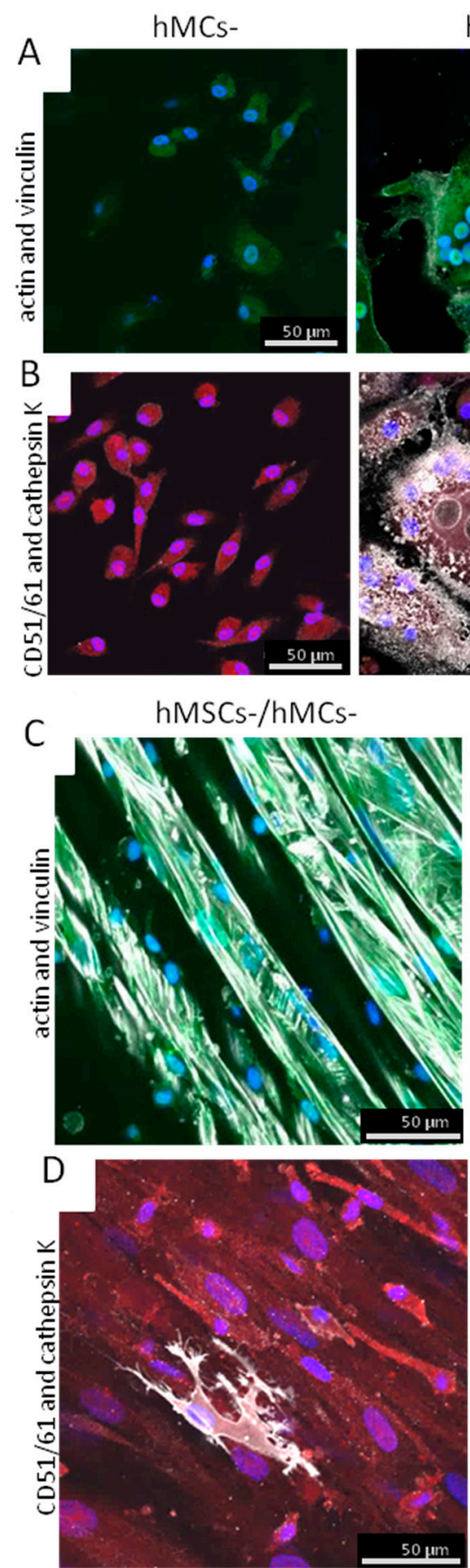

hMCs+
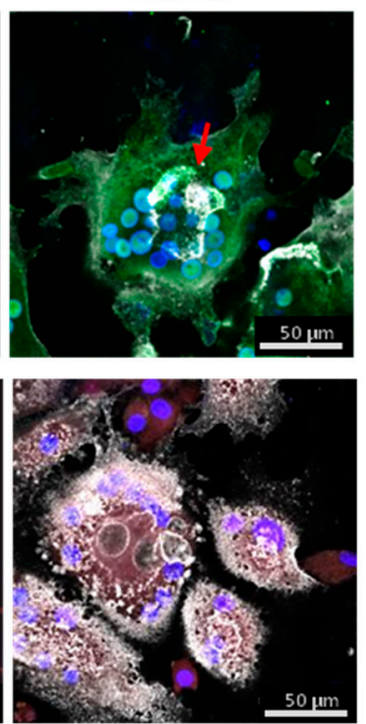

hMSCs-
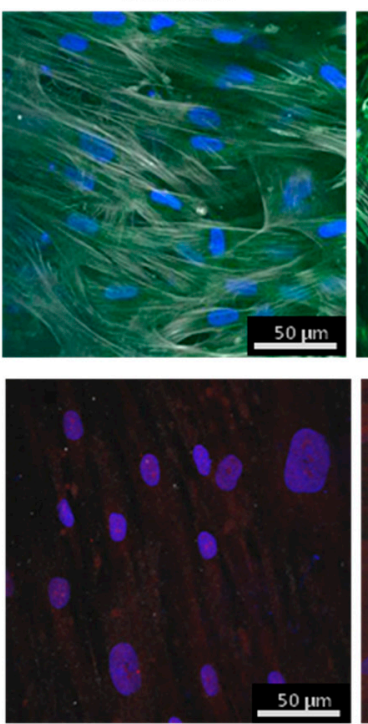

hMSCs+
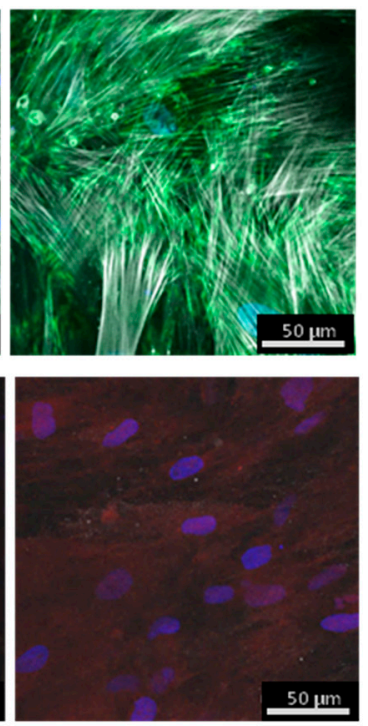

hMSCs+/hMCs+
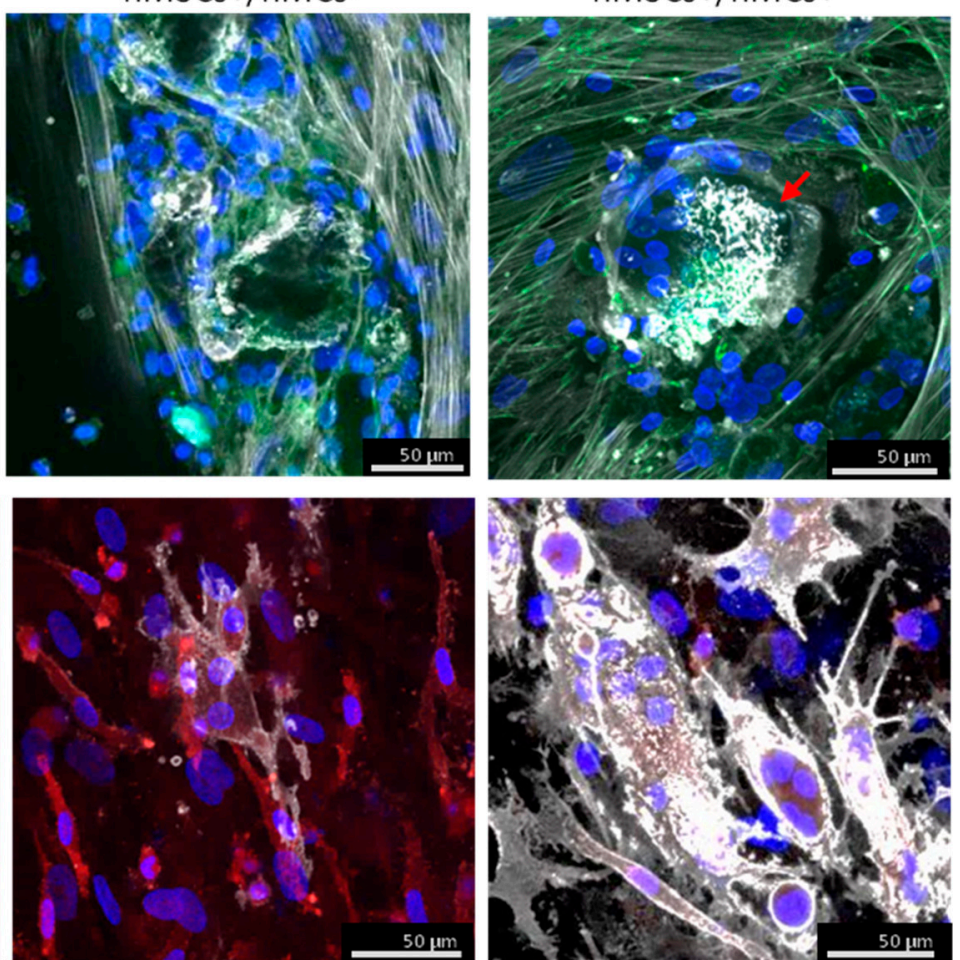

Figure 3. Morphological analysis of the osteoclastogenesis in different co-culture set-ups on BS after 14 days of co-culture. To analyze cell morphology an actin-vinculin staining (actin: white; vinculin: green) in mono- and co-cultures was performed (A,C). Single osteoclast-specific actin arrangements were seen in model II and more often in model III. Actin-rings in hMCs+ and co-culture model III are highlighted with red arrows. CD51/61 postive and cathepsin K-positive cells were detected in all co-culture models (CD51/61: white; cathepsin K: red) (B,D). The amount of cathepsin K stained cells was highest in model III.

\subsubsection{Analysis of Osteoclast-Specific Bone Resorption Activity in Co-Culture Set-Ups on BS}

To evaluate the resorption activity of osteoclasts, bone slices were analyzed concerning resorption pits, also known as howship's lacunae, after 14 days of co-culture. Therefore, the cells were detached, 
the BS were fixed, and SEM analysis was performed (Figure 4). Large Howship's lacunae, caused by active osteoclasts, were detected on BS cultured with hMCs+ (Figure 4A).

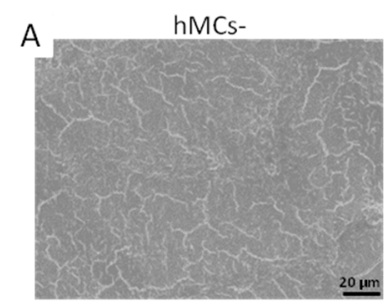

B

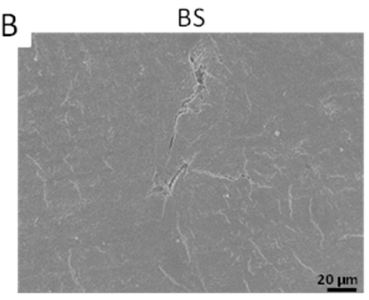

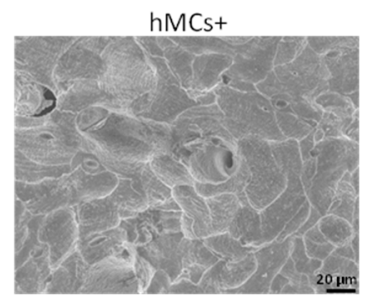

hMSCs-/hMCs-

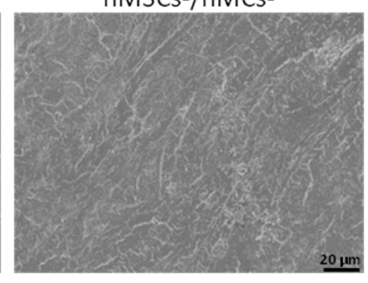

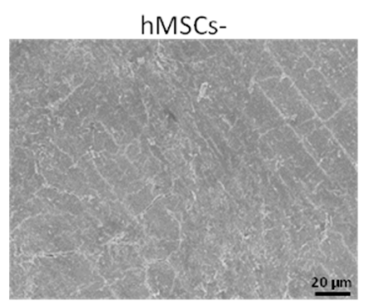

hMSCs+/hMCs-

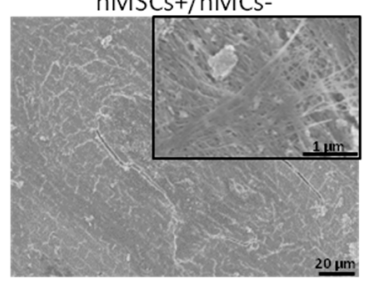

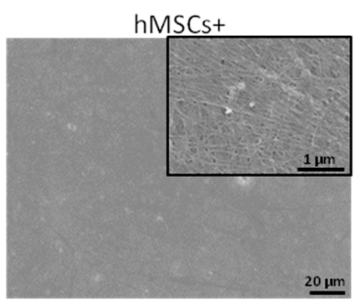

hMSCs+/hMCs+

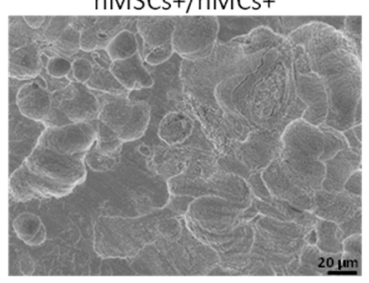

Figure 4. SEM analysis of resorption activity of osteoclasts on bone slices (BS) after 14 days of co-culture time. Cells were detached before analyzing the BS for the mono-culture (A) and the co-culture set-ups (B). Resorption pits can be seen on bone slices with former mono-culture of hMC+ and on bone slices of former co-culture model III. In the black box a higher magnification of the pictures is shown.

For all other mono-cultures, only a dense fiber network was seen on hMSCs+ set-ups, but no resorption pits were detected. Such network structures were also observed on the bone slices with former co-cultures on it (Figure 4B). In co-culture-set-up III, resorption pits were found. Comparing the resorption pits in the co-culture model III and the mono-culture, the ones on the co-culture set-up were more spherical, while resorption pits in the mono cell-culture were more aligned. The diameter that the resorption pits detected on BS for hMCs+ was $21.84 \pm 4.92 \mu \mathrm{m}$, while the diameter for the pits on BS with former hMCs+/hMCs+ culture was $23.29 \pm 6.67 \mu \mathrm{m}$.

\section{Discussion}

In vivo bone is remodeling permanently caused by osteoblasts and osteoclasts [31]. Co-culture models can mimic these processes in vitro. In our study, we focused on several co-culture set-ups to achieve functional osteoclasts. Therefore, our models were built-up on bovine bone materials to analyze not only the morphology and protein expression of achieved osteoclasts but, moreover, their bone resorption activity.

\subsection{Characterization of Isolated $h M C s$}

We used human monocytes and mesenchymal stem cells to establish co-culture models, which allowed us to analyze the development of active osteoclasts in presence of hMSCs or osteogenic differentiated hMSCs. hMCs were isolated from buffy coats and characterized during different isolation steps by flow cytometry. CD14 is a characteristic surface protein found on monocytes [24,25]. We detected $34 \%$ CD14-positive cells after $1.5 \mathrm{~h}$ of plastic adherence. Similar results are found in literature [32]. More recent studies showed that coating TCPS with albumin could increase further monocyte adhesion $[33,34]$.

CD45 is a type I transmembrane glycoprotein and a member of the protein tyrosine phosphatase family, which is present on all differentiated hematopoietic cells [35,36]. We detected nearly $99 \%$ of CD45-positive cells in our population, which means that most of our hMCs are not yet differentiated to osteoclasts. This is underlined by less than 1\% CD51/61-positive cells during the culture period. 
CD51/61 is produced in the adhesion domain of differentiated osteoclasts, which is why we used it as control and later for osteoclast-specific staining in the co-culture set-ups [27-30].

\subsection{Comparison of Osteoclast Generation on TCPS and BS}

We performed experiments to compare the differentiation of hMCs on TCPS and BS. Active osteoclasts were polarized with a basolateral and an apical cell-area. These large multinucleated cells had podosomes, lamellipodia, and filopodia actin formation and built different domains like a sealing zone and a ruffled border [10,37-39].

We could have shown these morphological characteristics for monocytes cultured in OC medium on TCPS and BS by staining actin and vinculin. Characteristic actin formation was seen only on BS. Takahashi and colleagues observed the same on mineralized matrices [10,40]. We detected vinculin staining overlaid with the actin rings, which revealed an extensive cell-extracellular matrix contact. This was also described by Saltel and colleagues [41]. No actin rings were detected in cells on TCPS, as osteoclasts adhere to artifical material that they can not resorb [10,42,43]. We believe TCPS is not suited for evaluating bone resorption functionality of osteoclasts, and, therefore, we built-up our subsequent co-culture models on bone-slices. Moreover, to determine the successful differentiation of hOCs, a staining of CD51/CD61 was performed.

As expected, no CD51/61-positive cells were detected in basic medium, whereas CD51/61-positive cells were detected on TCPS and BS after culture in OC medium. Cathepsin $\mathrm{K}$ staining was proved diffusely in the cytosol of hMCs in basic medium, but the intense was higher in generated osteoclasts in OC medium. On BS, we saw more cathepsin K-stained vesicles and granula, which corresponded to active osteoclasts. This was also shown by Avnet and Lamolinarat on glass and dentine [8]. For the evaluation of the bone resorption activity of hOCs, SEM analysis of bone slices was performed. The typical Howship's lacunae were detected after removing the cells from BS, which underlines the former occurrence of functional bone resorbing osteoclasts on our material.

\subsection{Different Co-Culture Set-Ups in Comparison}

Different co-culture models for MSCs/osteoblasts and osteoclasts are found in literature $[12,14,15,17,20]$. One system consists of hMSCs and generated osteoblasts cultured on two levels of membrane-like structures from mineralized collagen. Spatial separation of both cell types was done by transwell inserts, while exchange of soluble factors was still ensured. It was shown that in co-culture with hMSCs more osteoclasts could be generated, compared to the co-culture with osteoblasts [44].

In 1999, Mbalaviele and colleagues [45] worked on co-culture models with hMSCs from human bone marrow and CD34 ${ }^{+}$hematopoietic stem cells (HSCs). They tested different co-culture settings like separation of cells via membranes versus direct cell-cell contact, whereby the model with cell-cell contact yielded better results [45].

The co-culture model we tested was based on the co-culture model of Heinemann and colleagues [46]. hMCs were seeded on osteogenic differentiated hMSCs and co-cultured for 14 days, allowing direct cell-cell contact. Heinemann et al. [22] used L-ascorbic acid-2-phosphate, $\beta$-glycerophosphate, dexamethasone, and, in addition, vitamin $\mathrm{D}_{3}$, which influences the osteoclastic differentiation as well. Vitamin $\mathrm{D}_{3}$ was used before RANKL identification for in vitro generation of osteoclasts $[27,45,47,48]$.

Our aim was to build up co-culture models on bone slices that contained active osteoclasts. Besides, we evaluated the need for different supplements in our media dispensing vitamin $\mathrm{D}_{3}$. As a first characterization of the osteoclastogenesis in our models, we performed a staining of actin and vinculin to detect morphological changes in actin formation. Next, we performed a staining of proteins expressed in differentiated osteoclasts like CD51/61 and cathepsin K. Moreover, we evaluated the functional resorption activity of our osteoclasts by using bovine bone as substrate material for our co-cultures, which enabled us to analyze the occurrence of resorption pits. 
By cell labeling, we saw a much higher number of hMSCs than hMCs in our co-culture models. This was quite similar to the situation we have in vivo [49,50]. In addition, we proved the appearance of both cell types in our co-culture models during the whole culture time.

After staining actin and vinculin, we detected a change in actin formation in co-culture model II and III. While only single cells showed this actin restructuring in model II, more cells had an osteoclast-specific actin morphology with podosome belts and actin rings in model III. No cells with osteoclast-specific actin morphology were seen in model I. Active osteoclasts form a ring-like structure as adhesion domain on bone by $\alpha \mathrm{v} \beta 3$-integrin and build a sealing zone between the cell and the bone matrix. The cysteine protease cathepsin $\mathrm{K}$ is essential for bone resorption and is expressed by osteoclasts and released through the ruffled border into the resorption pit between cell and matrix [39,51].

We detected positively stained cells with cathepsin K granulates in all of our co-culture set-ups. Staining of this protease occurred even in cells without any osteoclast-specific morphology; wherefore, we believe cathepsin $\mathrm{K}$ is not sufficient to determine osteoclasts in co-culture systems. The results of the CD51/61 staining underlined the observation we made for the actin and vinculin staining. Only sporadic CD51/61 positive cells were seen in co-culture model I and II, but numerous intensively stained cells with osteoclast-specific morphology-like large and multinucleated cells were seen in model III. These outcomes were confirmed further by the final experiments that analyzed the resorption activity of the achieved osteoclasts in the co-culture models. No resorption pits were found on BS of model I and II, whereas on BS of model III resorption pits were detected. These pits were similar in geometry and diameter to the resorption pits seen in the mono-culture of hOCs and to the ones we reported earlier on different bone or bone like materials [10]. These results provided evidence of the presence of functional bone resorbing osteoclasts in our co-culture model.

Heinemann and colleagues [22] showed the formation of large multinuclear osteoclasts in their co-culture set-ups. However, in comparison to our study, they didn't perform an activity test to reveal the osteoclast resorption ability. Their cell culture was performed on xerogele, a combination of silicate, bovine collagen, and hydroxyapatite, and cells were analyzed by gene and protein expression and morphological observations [21].

A recent study by Schulze et al. presents a direct co-culture of hMSCs and hMCs on a SaOS-2-derived extracellular matrix [52]. This matrix was introduced as an alternative material for testing bone resorption activity of osteoclasts [53,54]. They revealed an increased resorption on these cell-derived matrices by generated active osteoclasts, even without the addition of RANKL and M-CSF to the cell culture medium.

In contrast to the study of Schulze et al., [52] we assume differentiation factors such as M-CSF and RANKL were not sufficiently expressed in our culture set-ups to create active OCs on BS without further supplementation. Only in model III, including M-CSF and RANKL in the media, characteristic actin formation, the expression of cathepsin K, and CD51/61 in multinuclear cells, as well as resorption pits, were seen on BS. It would be interesting to compare the BS and the SAOS-2-derived matrix regarding material properties and the resorption activity of osteoclasts on them. The proportion of cell amount could be an alternative optimization for our co-culture system to produce more osteoclastogenic factors like RANKL and M-CSF by hMSCs/ osteoblasts [45]. For further improvement of in vitro co-culture set-ups for bone remodeling of the culture media, the cell ratio and also the culture substrate are important factors that need to be considered. In particular, the bone resorption on native bone or bone-like materials should be evaluated as a real proof of functionality during osteoclastogenesis.

\section{Conclusions}

To determine osteoclastogenesis, our co-culture models were built-up on bovine bone material, which enabled us to perform the usual stainings and thereafter analyze the bone resorption activity of the cells in the co-culture set-ups. We successfully induced osteoclastogenesis, but active bone resorbing osteoclasts were achieved only by the addition of M-CSF and RANKL to the medium. Positive staining alone is not sufficient to determine functional osteoclasts in our opinion, as we detected 
more osteoclast-like cells by staining than we later found by analyzing the presence of resorption pits. The refinement of culture conditions is crucial to the outcome of cell development. By our study, we contributed highly to the improvement and definition of in vitro culture conditions for more sophisticated co-culture models. As other studies have demonstrated previously, the culture substrate influences osteoclastogenesis. Therefore, we suggest, for future studies, the use of bone materials as a standard material to compare the bone resorption functionality of the achieved osteoclasts.

Acknowledgments: We want to thank Sibylle Thude and Kirstin Linke for the technical support with the flow cytometry and Monika Riedl for the technical support during SEM analysis. This work was supported by the Fraunhofer Gesellschaft (Grant No. MAVO DegraLast 824682).

Author Contributions: Franziska Schmid performed the experiments and analyzed the data for Table 3, Figures 1-4, and prepared the manuscript. Claudia Kleinhans designed and co-supervised the experiments and prepared the manuscript. Freia Schmid performed some preliminary experiments and prepared the manuscript. Petra Kluger designed the study, supervised the experiments, and prepared the paper.

Conflicts of Interest: The authors declare no conflict of interest.

\section{References}

1. Salgado, A.J.; Coutinho, O.P.; Reis, R.L. Bone tissue engineering: State of the art and future trends. Macromol. Biosci. 2004, 4, 743-765. [CrossRef] [PubMed]

2. Hadjidakis, D.J.; Androulakis, I.I. Bone remodeling. Ann. N. Y. Acad. Sci. 2006, 1092, 385-396. [CrossRef] [PubMed]

3. Roodman, G.D. Cell biology of the osteoclast. Exp. Hematol. 1999, 27, 1229-1241. [CrossRef]

4. Roodman, G.D. Regulation of osteoclast differentiation. Ann. N. Y. Acad. Sci. 2006, 1068, 100-109. [CrossRef] [PubMed]

5. O'Brien, T. Nakashima, H. Takayanagi, Osteocyte control of osteoclastogenesis. Bone 2013, 54, $258-263$. [CrossRef] [PubMed]

6. Suda, T.; Takahashi, N.; Udagawa, N.; Jimi, E.; Gillespie, M.T.; Martin, T.J. Modulation of osteoclast differentiation and function by the new members of the tumor necrosis factor receptor and ligand families. Endocr. Rev. 1999, 20, 345-357. [CrossRef] [PubMed]

7. Cody, J.J.; Rivera, A.A.; Liu, J.; Liu, J.M.; Douglas, J.T.; Feng, X. A simplified method for the generation of human osteoclasts in vitro. Int. J. Biochem. Mol. Biol. 2011, 2, 183-189. [PubMed]

8. Avnet, S.; Lamolinara, A. Effects of antisense mediated inhibition of cathepsin K on human osteoclasts obtained from peripheral blood. J. Orthop. Res. 2006, 24, 1699-1708. [CrossRef] [PubMed]

9. Bronner, F.; Farach-Carson, M.C.; Rubin, J. Bone Resorption; Springer Science \& Business Media: Berlin/Heidelberg, Germany, 2006.

10. Kleinhans, C.; Schmid, F.F.; Schmid, F.V.; Kluger, P.J. Comparison of osteoclastogenesis and resorption activity of human osteoclasts on tissue culture polystyrene and on natural extracellular bone matrix in 2D and 3D. J. Biotechnol. 2015, 205, 101-110. [CrossRef] [PubMed]

11. Mercatali, L.; Spadazzi, C.; Miserocchi, G.; Liverani, C.; De, A.V.; Bongiovanni, A.; Recine, F.; Amadori, D.; Ibrahim, T. Development of a Human Preclinical Model of Osteoclastogenesis from Peripheral Blood Monocytes Co-cultured with Breast Cancer Cell Lines. J. Vis. Exp. 2017. [CrossRef] [PubMed]

12. Penolazzi, L.; Lolli, A.; Sardelli, L.; Angelozzi, M.; Lambertini, E.; Trombelli, L.; Ciarpella, F.; Vecchiatini, R.; Piva, R. Establishment of a 3D-dynamic osteoblasts-osteoclasts co-culture model to simulate the jawbone microenvironment in vitro. Life Sci. 2016, 152, 82-93. [CrossRef] [PubMed]

13. Iwamoto, Y.; Nishikawa, K.; Imai, R.; Furuya, M.; Uenaka, M.; Ohta, Y.; Morihana, T.; Itoi-Ochi, S.; Penninger, J.M.; Katayama, I.; et al. Intercellular Communication between Keratinocytes and Fibroblasts Induces Local Osteoclast Differentiation: A Mechanism Underlying Cholesteatoma-Induced Bone Destruction. Mol. Cell. Biol. 2016, 36, 1610-1620. [CrossRef] [PubMed]

14. Kang, Y.K.; Zhang, M.C. IL-23 promotes osteoclastogenesis in osteoblast-osteoclast co-culture system. Genet. Mol. Res. 2014, 13, 4673-4679. [CrossRef] [PubMed]

15. Mukherjee, A.; Rotwein, P. Selective signaling by Akt1 controls osteoblast differentiation and osteoblast-mediated osteoclast development. Mol. Cell. Biol. 2012, 32, 490-500. [CrossRef] [PubMed] 
16. Yao, Z.; Xing, L.; Qin, C.; Schwarz, E.M.; Boyce, B.F. Osteoclast precursor interaction with bone matrix induces osteoclast formation directly by an interleukin-1-mediated autocrine mechanism. J. Biol. Chem. 2008, 283, 9917-9924. [CrossRef] [PubMed]

17. Guihard, P.; Danger, Y.; Brounais, B.; David, E.; Brion, R.; Delecrin, J.; Richards, C.; Chevalier, S.; Redini, F.; Heymann, D.; et al. Induction of osteogenesis in mesenchymal stem cells by activated monocytes/macrophages depends on Oncostatin M signaling. Stem Cells 2012, 30, 762-772. [CrossRef] [PubMed]

18. Nicolaidou, V.; Wong, M.M.; Redpath, A.N.; Ersek, A.; Baban, D.F.; Williams, L.M.; Cope, A.P.; Horwood, N.J. Monocytes induce STAT3 activation in human mesenchymal stem cells to promote osteoblast formation. PLoS ONE 2012, 7, e39871. [CrossRef] [PubMed]

19. Pirraco, R.P.; Reis, R.L.; Marques, A.P. Effect of monocytes/macrophages on the early osteogenic differentiation of hBMSCs. J. Tissue Eng. Regen. Med. 2013, 7, 392-400. [CrossRef] [PubMed]

20. Zachos, C.; Steubesand, N.; Seekamp, A.; Fuchs, S.; Lippross, S. Co-cultures of programmable cells of monocytic origin and mesenchymal stem cells do increase osteogenic differentiation. J. Orthop. Res. 2014, 32, 1264-1270. [CrossRef] [PubMed]

21. Heinemann, C.; Heinemann, S.; Worch, H.; Hanke, T. Development of an osteoblast/osteoclast co-culture derived by human bone marrow stromal cells and human monocytes for biomaterials testing. Eur. Cell Mater. 2011, 21, 80-93. [CrossRef] [PubMed]

22. Heinemann, S.; Heinemann, C.; Wenisch, S.; Alt, V.; Worch, H.; Hanke, T. Calcium phosphate phases integrated in silica/collagen nanocomposite xerogels enhance the bioactivity and ultimately manipulate the osteoblast/osteoclast ratio in a human co-culture model. Acta Biomater. 2013, 9, 4878-4888. [CrossRef] [PubMed]

23. Kleinhans, C.; Barz, J.; Wurster, S.; Willig, M.; Oehr, C.; Müller, M.; Walles, H.; Hirth, T.; Kluger, P.J. Ammonia plasma treatment of polystyrene surfaces enhances proliferation of primary human mesenchymal stem cells and human endothelial cells. Biotechnol. J. 2013, 8, 327-337. [CrossRef] [PubMed]

24. Massey, H.M.; Flanagan, A.M. Human osteoclasts derive from CD14-positive monocytes. Br. J. Haematol. 1999, 106, 167-170. [CrossRef] [PubMed]

25. Nicholson, G.C.; Malakellis, M.; Collier, F.M.; Cameron, P.U.; Holloway, W.R.; Gough, T.J.; Gregorio-King, C.; Kirkland, M.A.; Myers, D.E. Induction of osteoclasts from CD14-positive human peripheral blood mononuclear cells by receptor activator of nuclear factor kappaB ligand (RANKL). Clin. Sci. Lond. 2000, 99, 133-140. [CrossRef]

26. Walter, G.J.; Evans, H.G.; Menon, B.; Gullick, N.J.; Kirkham, B.W.; Cope, A.P.; Geissmann, F.; Taams, L.S. Interaction with activated monocytes enhances cytokine expression and suppressive activity of human $\mathrm{CD}_{4}{ }^{+} \mathrm{CD}_{45} \mathrm{RO}^{+} \mathrm{CD}_{25}{ }^{+} \mathrm{CD}_{127}{ }^{\text {low }}$ regulatory T cells. Arthritis Rheum. 2013, 65, 627-638. [CrossRef] [PubMed]

27. Quinn, J.M.W.; Fujikawa, Y.; McGee, J.O.D.; Athanasou, N.A. Rodent osteoblast-like cells support osteoclastic differentiation of human cord blood monocytes in the presence of M-CSF and 1,25 dihydroxyvitamin D3. Int. J. Biochem. Cell Biol. 1997, 29, 173-179. [CrossRef]

28. Heinemann, E.; Siggelkow, H.; Ponce, L.M.; Viereck, V.; Wiese, K.G.; Peters, J.H. Alkaline phosphatase expression during monocyte differentiation. Overlapping markers as a link between monocytic cells, dendritic cells, osteoclasts and osteoblasts. Immunobiology 2000, 202, 68-81. [CrossRef]

29. Meyer, U.; Meyer, T.; Handschel, J.; Wiesmann, H. Fundamentals of Tissue Engineering and Regenerative Medicine; Springer Science \& Business Media: Berlin/Heidelberg, Germany, 2009.

30. Sekine, C.; Koyanagi, A.; Koyama, N.; Hozumi, K.; Chiba, S.; Yagita, H. Differential regulation of osteoclastogenesis by Notch2/Delta-like 1 and Notch1/Jagged1 axes. Arthritis Res. Ther. 2012, $14, \mathrm{R} 45$. [CrossRef] [PubMed]

31. Udagawa, N.; Takahashi, N.; Jimi, E.; Matsuzaki, K.; Tsurukai, T.; Itoh, K.; Nakagawa, N.; Yasuda, H.; Goto, M.; Tsuda, E.; et al. Osteoblasts/stromal cells stimulate osteoclast activation through expression of osteoclast differentiation factor/RANKL but not macrophage colony-stimulating factor. Bone 1999, 25, 517-523. [CrossRef]

32. Bernhardt, A.; Schumacher, M.; Gelinsky, M. Formation of osteoclasts on calcium phosphate bone cements and polystyrene depends on monocyte isolation conditions. Tissue Eng. Part C Methods 2014, 21, 160-170. [CrossRef] [PubMed] 
33. Capasso, R.; Sambri, I.; Cimmino, A.; Salemme, S.; Lombardi, C.; Acanfora, F.; Satta, E.; Puppione, D.L.; Perna, A.F.; Ingrosso, D. Homocysteinylated albumin promotes increased monocyte-endothelial cell adhesion and up-regulation of MCP1, Hsp60 and ADAM17. PLoS ONE 2012, 7, e31388. [CrossRef] [PubMed]

34. Babaei, S.; Fekete, N.; Hoesli, C.A.; Girard-Lauriault, P.-L. Adhesion of Human Monocytes to Oxygen- and Nitrogen- containing Plasma Polymers: Effect of Surface Chemistry and Protein Adsorption. Colloids Surfaces $B$ Biointerfaces 2017, 162, 362-369. [CrossRef] [PubMed]

35. Saunders, E.; Johnson, P. Modulation of immune cell signalling by the leukocyte common tyrosine phosphatase, CD45. Cell. Signal. 2010, 22, 339-348. [CrossRef] [PubMed]

36. Hermann, P.; Armant, M.; Brown, E.; Rubio, M.; Ishihara, H.; Ulrich, D.; Caspary, R.G.; Lindberg, F.P.; Armitage, R.; Maliszewski, C.; et al. The vitronectin receptor and its associated CD47 molecule mediates proinflammatory cytokine synthesis in human monocytes by interaction with soluble CD23. J. Cell Biol. 1999, 144, 767-775. [CrossRef] [PubMed]

37. Takahashi, N.; Ejiri, S.; Yanagisawa, S.; Ozawa, H. Regulation of osteoclast polarization. Odontology 2007, 95, 1-9. [CrossRef] [PubMed]

38. Ciobanasu, C.; Faivre, B.; Le Clainche, C. Actin dynamics associated with focal adhesions. Int. J. Cell Biol. 2012, 2012, 941292. [CrossRef] [PubMed]

39. Takito, J.; Otsuka, H.; Inoue, S.; Kawashima, T.; Nakamura, M. Symmetrical retrograde actin flow in the actin fusion structure is involved in osteoclast fusion. Biol. Open 2017, 6, 1104-1114. [CrossRef] [PubMed]

40. Takahashi, N.; Udagawa, N.; Kobayashi, Y.; Suda, T. Generation of osteoclasts in vitro; assay of osteoclast activity. Methods Mol. Med. 2007, 135, 285-301. [PubMed]

41. Saltel, F.; Destaing, O.; Bard, F. Apatite-mediated actin dynamics in resorbing osteoclasts. Mol. Biol. 2004, 15, 5231-5241. [CrossRef] [PubMed]

42. Song, R.L.; Liu, X.Z.; Zhu, J.Q.; Zhang, J.M.; Gao, Q.; Zhao, H.Y.; Sheng, A.Z.; Yuan, Y.; Gu, J.H.; Zou, H.; et al. New roles of filopodia and podosomes in the differentiation and fusion process of osteoclasts. Genet. Mol. Res. 2014, 13, 4776-4787. [CrossRef] [PubMed]

43. Matsumoto, T.; Nagase, Y.; Hirose, J.; Tokuyama, N.; Yasui, T.; Kadono, Y.; Ueki, K.; Kadowaki, T.; Nakamura, K.; Tanaka, S. Regulation of bone resorption and sealing zone formation in osteoclasts occurs through protein kinase B-mediated microtubule stabilization. J. Bone Miner. Res. 2013, 28, 1191-1202. [CrossRef] [PubMed]

44. Bernhardt, A.; Thieme, S.; Domaschke, H.; Springer, A.; Rösen-Wolff, A.; Gelinsky, M. Crosstalk of osteoblast and osteoclast precursors on mineralized collagen-towards an in vitro model for bone remodeling. J. Biomed. Mater. Res. A 2010, 95, 848-856. [CrossRef] [PubMed]

45. Mbalaviele, G.; Jaiswal, N.; Meng, A.; Cheng, L.; Van Den Bos, C.; Thiede, M. Human mesenchymal stem cells promote human osteoclast differentiation from CD34+ bone marrow hematopoietic progenitors. Endocrinology 1999, 140, 3736-3743. [CrossRef] [PubMed]

46. Heinemann, C.; Heinemann, S.; Bernhardt, A. In vitro osteoclastogenesis on textile chitosan scaffold. Eur. Cell Mater. 2010, 19, 96-106. [CrossRef] [PubMed]

47. Takahashi, N.; Akatsu, T.; Udagawa, N.; Sasaki, T.; Yamaguchi, A.; Moseley, J.M.; Martin, T.J.; Suda, T. Osteoblastic cells are involved in osteoclast formation. Endocrinology 1988, 123, 2600-2602. [CrossRef] [PubMed]

48. Jäger, M.; Fischer, J.; Dohrn, W.; Li, X.; Ayers, D.C.; Czibere, A.; Prall, W.C.; Lensing-Höhn, S.; Krauspe, R. Dexamethasone modulates BMP-2 effects on mesenchymal stem cells in vitro. J. Orthop. Res. 2008, 26, 1440-1448. [CrossRef] [PubMed]

49. Turgeman, G.; Pittman, D.D.; Mueller, R.; Gowda Kurkalli, B.; Zhou, S.; Pelled, G.; Peyser, A.; Zilberman, Y.; Moutsatsos, I.K.; Gazit, D. Engineered human mesenchymal stem cells: a novel platform for skeletal cell mediated gene therapy. J. Gene Med. 2001, 3, 240-251. [CrossRef]

50. Artmann, G.M.; Minger, S.; Hescheler, J. Stem Cell Engineering: Principles and Applications; Springer Science \& Business Media: Berlin/Heidelberg, Germany, 2010.

51. Shugg, R.P.P.; Thomson, A.; Tanabe, N.; Kashishian, A.; Steiner, B.H.; Puri, K.D.; Pereverzev, A.; Lannutti, B.J.; Jirik, F.R.; Dixon, S.J.; et al. Effects of isoform-selective phosphatidylinositol 3-kinase inhibitors on osteoclasts: actions on cytoskeletal organization, survival and resorption. J. Biol. Chem. 2013, 288, 35346-35357. [CrossRef] [PubMed] 
52. Schulze, S.; Wehrum, D.; Dieter, P.; Hempel, U. A supplement-free osteoclast-osteoblast co-culture for pre-clinical application. J. Cell. Physiol. 2017, 1-10. [CrossRef] [PubMed]

53. Lutter, A.-H.; Hempel, U.; Wolf-Brandstetter, C.; Garbe, A.I.; Goettsch, C.; Hofbauer, L.C.; Jessberger, R.; Dieter, P. A novel resorption assay for osteoclast functionality based on an osteoblast-derived native extracellular matrix. J. Cell. Biochem. 2010, 109, 1025-1032. [PubMed]

54. Battiston, K.G.; Cheung, J.W.C.; Jain, D.; Santerre, J.P. Biomaterials in co-culture systems: Towards optimizing tissue integration and cell signaling within scaffolds. Biomaterials 2014, 35, 4465-4476. [CrossRef] [PubMed] 